\title{
Relations Between Adaptive and Maladaptive Perfectionism, Self-Efficacy, and Subjective Well-Being
}

\author{
Renāte Buliṇa \\ University of Latvia, Riga, Latvia
}

\begin{abstract}
This study investigated how perfectionism is connected to general self-efficacy and subjective well-being. Two hypotheses were put forward: (1) Adaptive perfectionism is positively linked with self-efficacy and subjective well-being; and (2) Maladaptive perfectionism is negatively linked with self-efficacy and subjective well-being. The participants were 254 persons aged 18 years and above (average age $M=24.63, S D=5.30$ ), $76.8 \%$ of the participants were female and $23.2 \%$ were male. To collect data, these methods were used: General Self-Efficacy Scale (Schwarzer \& Jerusalem, 1995), APS-R (Almost Perfect Scale-Revised Short Form) (Slaney, Mobley, Trippi, Ashby, \& Johnson, 1996) - Both scales were translated and adapted to Latvian in this study, Latvian version of Positive and Negative Affect Schedule (Upmane, 2009), and Latvian version of Satisfaction with Life Scale (Maslovska, Voitkāne, Miezīte, \& Raščevska, 2005). The results show that adaptive perfectionism is linked with higher self-efficacy, higher positive emotions, and less negative emotions, in turn, maladaptive perfectionism is linked with lower self-efficacy, lower positive emotions, and higher negative emotions. In addition, level of self-efficacy and positive and negative emotions for maladaptive perfectionists does not have statistically significant differences from nonperfectionists indicators, complementing existing research that suggests perfectionism has adaptive and maladaptive components. However, satisfaction with life indicators show that there are no statistically significant differences between groups of the adaptive, maladaptive perfectionism and nonperfectionism.
\end{abstract}

Keywords: adaptive perfectionism, maladaptive perfectionism, nonperfectionism, self-efficacy, subjective well-being

\section{Introduction}

In recent decades, there has been increasing interest among the researchers in positive aspects of self-efficacy and subjective well-being, rather than the absence or insufficiency of those. In a similar vein, the pressure from environment to achieve more, do better, and avoid mistakes has highlighted the scientific research of perfectionism, eventually expanding the concept and exploring its aspects and dimensions in more detail. Attempts are made to reach an unequivocal confirmation of the idea that perfectionism is not only a negative, destructive feature, but it also has an adaptive value that can positively affect the work performance, as well as the overall quality of life.

Renāte Buliņa, Mg.Psych., Department of Pscyhology, University of Latvia. 


\section{Perfectionism}

Initially perfectionism was considered as a one-dimensional construct associated with psychopathology and it was considered a symptom of personality disorder (Stoeber \& Otto, 2006). David Burns (Burns, 1980) defined a perfectionist as someone who sets standards much higher than the possible attainable level or higher than the actual need for a given performance and whose lifestyle may be characterized by a compulsive and relentless commitment to achieve the set goals.

In 1990s, researchers started to conceptualize perfectionism as a multi-dimensional construct, for example, Randy Frost with colleagues developed the Frost Multidimensional Perfectionism Scale (Frost, Marten, Lahart, \& Rosenblate, 1990) which distinguishes six aspects of perfectionism: concern over mistakes, personal standards, parental expectations, parental criticism, doubts about actions, and organization. In turn, Paul Hewitt and Gordon Flett developed Multidimensional Perfectionism Scale (Hewitt \& Flett, 1991) that rates three aspects of perfectionistic self-presentation: self-oriented perfectionism, other-oriented perfectionism, and socially prescribed perfectionism.

While there were changes in perceiving perfectionism as a multi-dimensional construct, still most of the research studies continued to assess perfectionism as a negative, unwanted feature. Polarity of perfectionism is still the controversial point; some authors doubt the idea that perfectionism could be positive, functional or adaptive, but there are some new conceptions developed that divide perfectionism into positive and negative component, emphasizing and grounding it on research findings that both parts differ from each other (Egan, Piek, Dyck, \& Rees, 2007). The positive aspect of perfectionism is described as goal setting and striving for the reward and recognition while maintaining the flexibility and satisfaction with oneself. In turn, the negative aspect of perfectionism is characterized by very high and rigid goal setting, high standards, inability to feel satisfaction, and distress about lost opportunities (Khawaja \& Armstrong, 2005).

\section{Self-Efficacy}

The concept of self-efficacy was introduced by Albert Bandura referring to a dynamic cognitive process that can be described as a belief in one's ability, successful expression of the required behavior in a given situation by mobilizing motivation and cognitive resources (Wood \& Bandura, 1989). The level of self-efficacy determines how much effort and time an individual will dedicate in attempting to fulfil the task (Lackaye \& Margalit, 2008). Individuals with high level of self-efficacy are aware that they are able to overcome obstacles and focus on opportunities. In this way, self-efficacy leads individuals to effective problem-solving (Luszczynska, Gutiérrez-Dona, \& Schwarzer, 2005). Self-efficacy characterizes person's belief in ability to control challenging requirements and own functioning (Luszczynska et al., 2005).

\section{Subjective Well-being}

Subjective well-being is defined as "a person's cognitive and affective evaluations of his or her life" (Diener, Oshi, \& Lucas, 2002, p. 63). The cognitive element refers to what one thinks about his or her life satisfaction in global terms (life as a whole) and in domain terms (in specific areas of life such as work, relationships, etc.). The affective element refers to emotions, moods, and feelings. Affect is considered positive when the emotions, moods, and feelings experienced are pleasant (e.g., joy, elation, affection, etc.). Affect is deemed negative, though, when the emotions, moods and feelings experienced are unpleasant (e.g., guilt, anger, 
shame etc.) (Diener et al., 2003; Pavot \& Diener, 2004).

Even though in recent years, there have been several studies, which have successfully demonstrated that perfectionism is not a clear abnormality and has adaptive aspects (Rice \& Stuart, 2010), most studies continue to focus on cognition of the maladaptive aspect. So far few studies have examined how both these aspects of perfectionism affect subjective well-being or life satisfaction. There are also relatively few studies that investigate relationship between self-efficacy and perfectionism, not to mention the studies that deal with interrelation of all three of these phenomena. The goal of this study was to clarify how perfectionism is linked to general self-efficacy and subjective well-being.

Two hypotheses were put forward:

(1) Adaptive perfectionism is positively linked with self-efficacy and subjective well-being;

(2) Maladaptive perfectionism is negatively linked with self-efficacy and subjective well-being.

\section{Material and Method}

\section{Participants}

The study surveyed 254 adult respondents aged 18 years and above (average age $M=24.63, S D=5.30$ ), $76.8 \%$ of the respondents were female and $23.2 \%$ were male. Forty-six point one percent respondents have higher education, $39.4 \%$ have incomplete higher education, $11.8 \%$ have secondary education, and $2.8 \%$ of respondents have primary education.

\section{Instruments}

General Self-Efficacy Scale. The one-dimensional 10-item scale was created to assess a general sense of perceived self-efficacy - to measure an individual's optimistic judgments about their ability to cope with a variety of difficult demands in life (Schwarzer \& Jerusalem, 1995). This scale was translated and adapted to Latvian in this study.

APS-R (Almost Perfect Scale-Revised Short Form). It is a 23 -item scale witch was developed to measure the negative and positive aspects of perfectionism (Slaney et al., 1996). The APS-R consists of three subscales: "High Standards" (7 items), "Discrepancy" (12 items), and "Order" (4 items). If the respondent has high results on the high standards and order subscales, then the respondent is considered as an adaptive perfectionist, but, if the respondent has high results on all three subscales (high standards, discrepancy, and order), it is considered that respondent is a maladaptive perfectionist. If the respondent does not meet the criteria mentioned above, then it is considered that he or she is a non-perfectionist. For the purpose of this study, the APS-R was translated and adapted to Latvian.

PANAS (Positive and Negative Affect Schedule). It is a self-report survey developed to measure the positive and negative affect (Watson, Clark, \& Tellegen, 1988). PANAS consists of two 10-item subscales. Respondents are asked to rate the extent to which they have experienced each particular emotion within a specified time period. In this study, the Latvian version of PANAS (Upmane, 2009) was used to measure the affective aspect of subjective well-being.

SWLS (Satisfaction with Life Scale). It was developed to measure individuals' general judgments about their lives (Diener, Emmons, Larson, \& Griffin, 1985). In this study, the Latvian version of SWLS scale was used to measure the life satisfaction as a factor of subjective well-being. Latvian version was adapted by group of authors (Maslovska, Voitkāne, Miezīte, \& Raščevska, 2005). 


\section{Procedure}

Participants completed the Internet-based survey set and information about its location was published electronically on several social sites and web pages, which allowed interested parties to complete the survey. All responses were anonymous and confidential.

\section{Results}

For each survey, the mean, the standard deviation, and Cronbach's alpha were calculated as well as Kolmogorov-Smirnov test to determine if the empirical distribution deviates from normal distribution (see Table 1). Cronbach's alphas indicates that all measures have high reliability and internal consistency.

Table 1

Means, SD (Standard Deviations), Cronbach's Alphas, Kolmogorov-Smirnov Z for General Self-Efficacy Scale, $A P S-R, P A N A S$, and SWLS

\begin{tabular}{lllllll}
\hline & $N$ & $M$ & $S D$ & Cronbach's alpha & Kolmogorov-Smirnov $Z$ & Asymp. Sig. (2-tailed) \\
\hline High standards & 254 & 36.65 & 6.49 & 0.83 & 1.41 & 0.04 \\
Order & 254 & 21.17 & 4.56 & 0.82 & 2.28 & 0.00 \\
Discrepancy & 254 & 45.65 & 15.93 & 0.93 & 0.78 & 0.58 \\
Self-efficacy & 254 & 29.32 & 4.65 & 0.86 & 1.30 & 0.07 \\
Positive affect & 254 & 34.88 & 6.52 & 0.85 & 1.34 & 0.06 \\
Negative affect & 254 & 27.00 & 7.51 & 0.86 & 1.29 & 0.07 \\
Satisfaction with life & 254 & 21.96 & 6.07 & 0.82 & 0.93 & 0.35 \\
\hline
\end{tabular}

The results show statistically significant positive correlation between self-efficacy and life satisfaction $(r=$ $0.24, p<0.01)$, positive affect $(r=0.41, p<0.01)$, and negative correlation with negative affect $(r=-0.26, p<$ $0.01)$. Self-efficacy also correlated with high standards $(r=0.27, p<0.01)$ and correlated negatively with discrepancy $(r=-0.20, p<0.01)$. Discrepancy correlated positively with negative affect $(r=0.39, p<0.01)$, and negatively with life satisfaction $(r=-0.28, p<0.01)$ and positive affect $(r=-0.29, p<0.01)$.

To test the hypothesis, all respondents were divided into three groups: adaptive perfectionists $(N=30)$, maladaptive perfectionists $(N=44)$, and non-perfectionists $(N=180)$ based on the results of the perfectionism scale. For each group, the mean values and standard deviations were calculated (see Table 2).

Table 2

Means and SD for General Self-Efficacy Scale, APS-R, PANAS, and SWLS for Adaptive, Maladaptive and Non-Perfectionism Groups

\begin{tabular}{|c|c|c|c|c|c|c|}
\hline & \multicolumn{2}{|c|}{$\begin{array}{l}\text { Adaptive perfectionism group } \\
\qquad(N=30)\end{array}$} & \multicolumn{2}{|c|}{$\begin{array}{l}\text { Maladaptive perfectionism } \\
\quad \text { group }(N=44)\end{array}$} & \multicolumn{2}{|c|}{$\begin{array}{c}\text { Non-perfectionism group } \\
\qquad(N=180)\end{array}$} \\
\hline & $M$ & $S D$ & $M$ & $M$ & $S D$ & $S D$ \\
\hline High standards & 41.13 & 2.46 & 42.75 & 34.42 & 6.29 & 2.54 \\
\hline Order & 25.33 & 1.85 & 24.98 & 19.55 & 4.36 & 1.69 \\
\hline Discrepancy & 33.63 & 9.78 & 60.68 & 43.97 & 15.22 & 11.03 \\
\hline Self-efficacy & 32.00 & 3.84 & 29.71 & 28.77 & 4.69 & 4.35 \\
\hline Positive affect & 37.90 & 5.94 & 33.91 & 34.62 & 6.78 & 5.19 \\
\hline Negative affect & 23.77 & 7.04 & 29.34 & 26.96 & 7.32 & 7.89 \\
\hline Satisfaction with life & 24.10 & 5.99 & 22.07 & 21.58 & 6.13 & 5.64 \\
\hline
\end{tabular}


For each measure, ANOVA (one independent factor analysis of variance) and post-hoc analysis were conducted to compare three groups.

\section{General Self-Efficacy}

The ANOVA of general self-efficacy indicated that there are significant differences between groups $F(2,251)=6.68, p<0.01$ (see Figure 1). Post-hoc analysis showed that self-efficacy scores for adaptive perfectionism group $(M=32)$ were significantly higher than those of the maladaptive perfectionism group $(M=29.71)$ and non-perfectionism group $(M=28.77)$, but there was no statistically significant difference in the scores of self-efficacy between maladaptive perfectionism and non-perfectionism groups $(p>0.05)$.

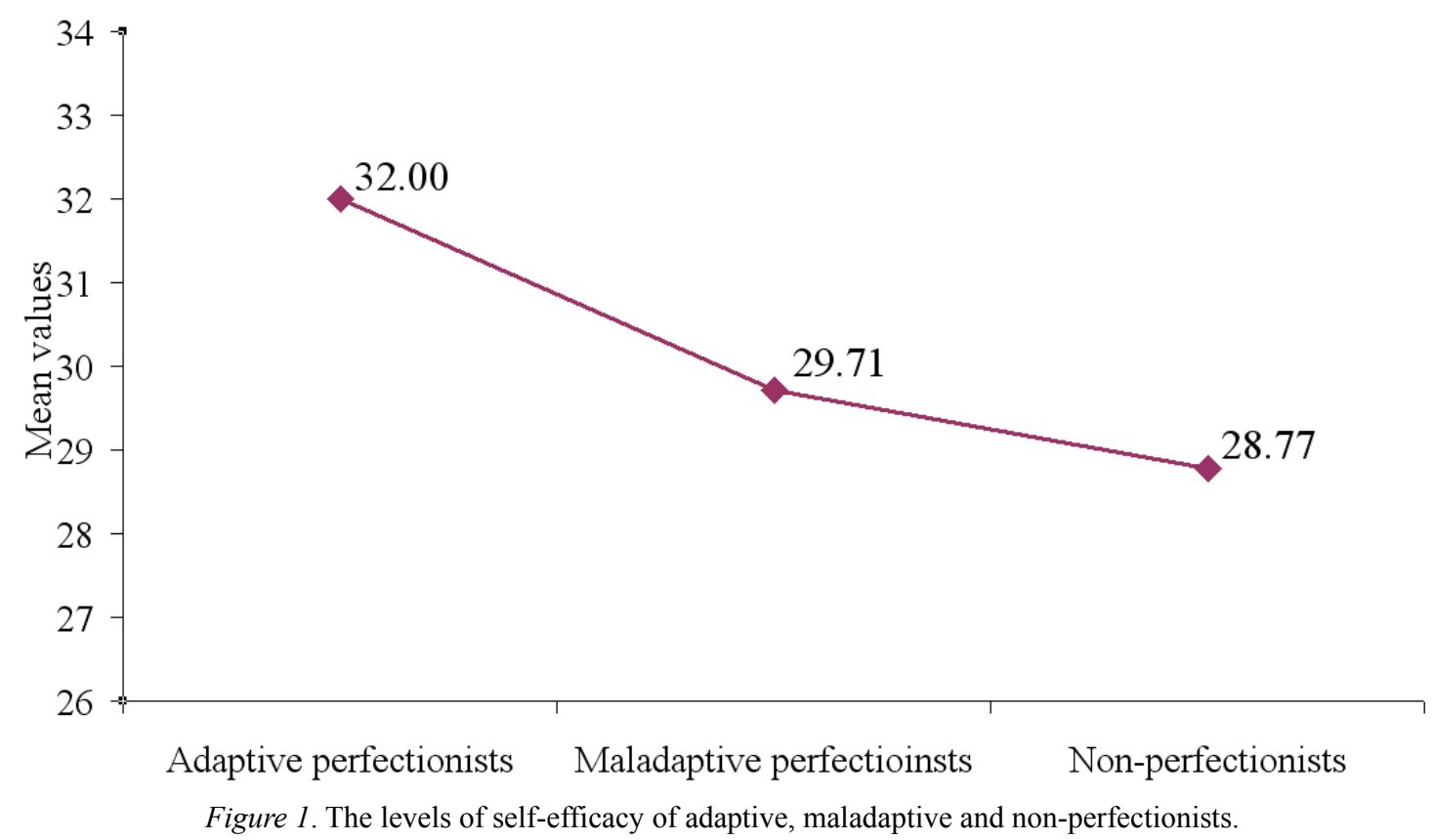

\section{Subjective Well-being}

By contrast, life satisfaction indicators in ANOVA showed that there are no statistically significant differences between all three groups results, $F(2,251)=2.25, p=0.11$. In order to better understand the construct of subjective well-being, the affective aspect of it has to be observed. The ANOVA of positive affect results indicated that there are significant differences between groups $F(2,251)=3.95, p<0.05$.

Adaptive perfectionism group had significantly higher scores of positive affect $(M=37.90)$ than maladaptive perfectionism group $(M=33.91)$ and non-perfectionism group $(M=34.62)$, but there was no statistically significant difference in the scores of positive affect between maladaptive perfectionism and non-perfectionism groups $(p>0.05)$. The ANOVA of negative affect results also indicated that there are significant differences between groups $F(2,251)=5.08, p<0.01$. Post-hoc analysis showed that positive affect scores for adaptive perfectionism group $(M=23.77)$ were significantly lower than those of the maladaptive perfectionism group $(M=29.34)$, but similar to non-perfectionism group scores $(M=26.96)$. There was no statistically significant difference in the scores of negative affect between maladaptive perfectionism and non-perfectionism groups $(p>0.05)$ (see Figure 2). 


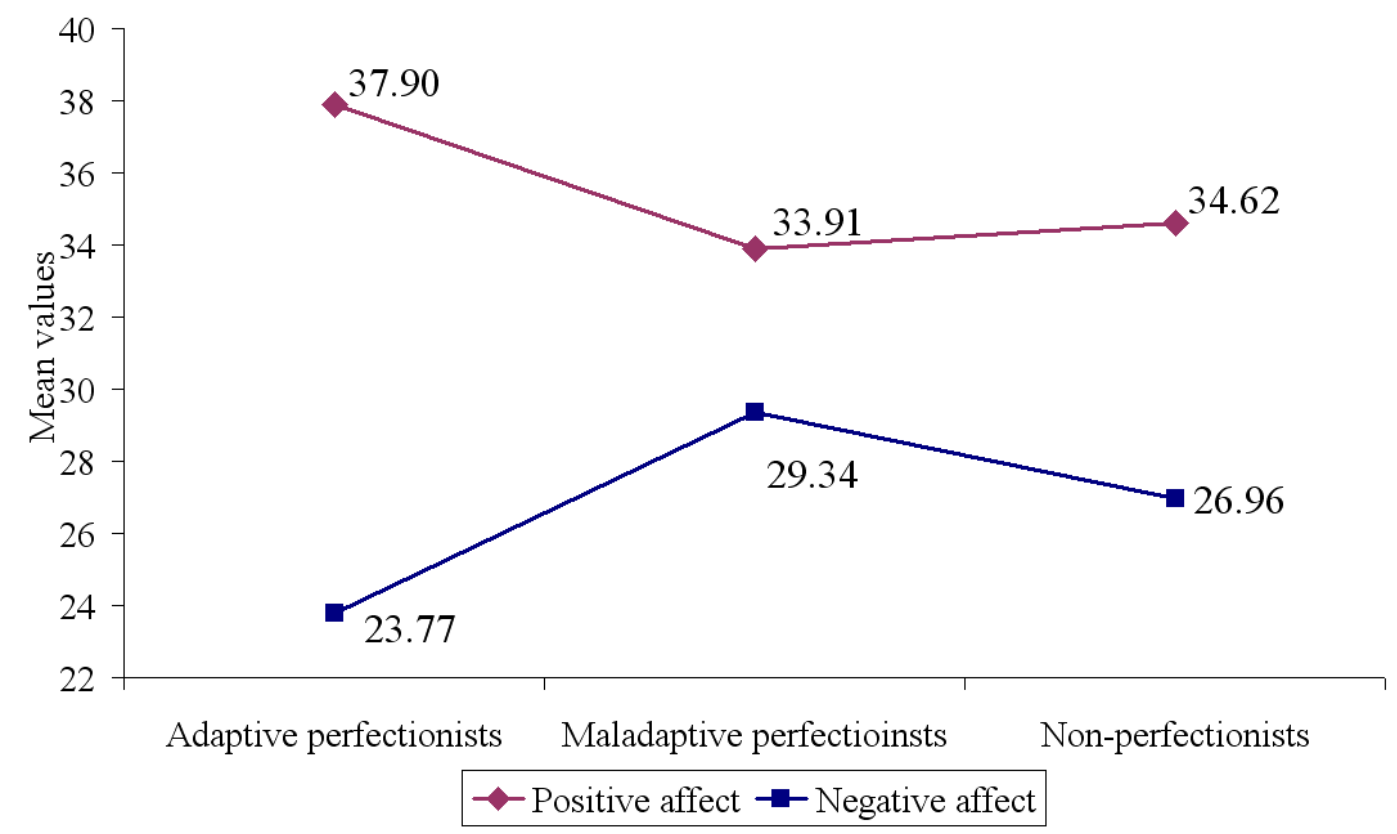

Figure 2. Levels of positive and negative affect of adaptive, maladaptive and non-perfectionists.

\section{Discussion and Conclusion}

The results of the current study show that adaptive perfectionism is associated with higher self-efficacy, higher positive affect, and lower negative affect, however, the indicators of subjective well-being do not statistically significantly differ between adaptive, maladaptive perfectionists and non-perfectionists. Thus, the first hypothesis of the study is partially confirmed. The relation between adaptive perfectionism and self-efficacy is also supported by positive correlation between self-efficacy and APS-R high standards subscale, which measures the individual's high expectations of themselves and their performance and the pursuit of excellence, supporting theoretical approaches and some previous studies that individuals with higher self-efficacy set themselves more challenging and ambitious targets, and they are more persistent in meeting their goals (Lusczynska et al., 2005; Schyns, 2004).

The results also show that maladaptive perfectionism is associated with lower self-efficacy, lower positive affect, and higher negative affect rates, compared with adaptive perfectionism group, thus partially confirming the second hypothesis. However, if the results of maladaptive perfectionism group are compared with non-perfectionism group, they are similar and do not statistically significantly differ between these two groups.

The results concur with other authors' previous findings, which showed that adaptive and maladaptive perfectionists' levels of self-efficacy are significantly different and that adaptive perfectionists' self-efficacy is higher than the maladaptive perfectionists' and non-perfectionists' self-efficacy while maladaptive perfectionists' and non-perfectionists' self-efficacy levels are similar (LoCicero \& Ashby, 2000; Ganske \& Ashby, 2007). Perhaps it is because the adaptive perfectionists when striving for excellence reach objectively more unlike other individuals, even if the final goal has not yet been achieved. Also, studies have confirmed that adaptive perfectionism is associated with higher academic achievements and plans to continue studies (Bieling et al., 2003). Such achievements allow adaptive perfectionists to realize their potential and thus make a positive judgment about their own achievements of the performance, which positively influences self-efficacy, and thus 
could explain positive relations between both constructs. Moreover, adaptive perfectionists do not consider that their performance is never good enough, so they are able to recognize what has already been achieved and done even if the ultimate goal, perfection, has not yet been reached.

The maladaptive perfectionism group has higher level of negative effect than non-perfectionism group, but these levels are not statistically significantly different, therefore, it cannot be claimed that between all groups the maladaptive perfectionism group has the highest negative affect level which would significantly distinguish this particular group from the other two groups; at most, there is such a tendency. Assumedly, these differences would appear if groups of maladaptive and adaptive perfectionists had more respondents and all three groups would have similar number of participants.

The results support the latest theories about dual nature of the perfectionism and fit the new perspective established in the past decade of viewing perfectionism not only as a negative trait, but trying to understand all of perfectionism's aspects in relation with other constructs. This, in turn, allows to initiate a discussion on the idea that adaptive perfectionism not only does not interfere with the individual in his or her daily activities, but may even motivate him or her to do more, reach higher goals and have higher self-efficacy compared with individuals who do not have high levels of perfectionism, in other words, nonperfectionists. Moreover, regardless of whether an individual is a maladaptive perfectionist or non-perfectionist, his or her self-efficacy indicators are expected to be approximately at the same level. However, in author's opinion, these discussions may be quite unpredictable, because in the field of perfectionism studies, there is as yet no consensus on how perfectionism is really formed and what factors influence its development. The boundary between adaptive and maladaptive perfectionism has not been established yet. There is not any clear indication in scientific literature of whether and how adaptive perfectionism can become maladaptive and vice versa. Therefore, the cultivation of adaptive perfectionism, for example in children and adolescents, can lead to a situation where it turns into maladaptive perfectionism and produces a negative emotional context, because we cannot be sure whether the high goals will not eventually become too high and rigid, and whether it would trigger self accusations and anxiety if these goals would not be reached.

Summarizing the results, the general conclusions are as follows:

(1) Adaptive perfectionism is associated with higher self-efficacy, higher positive emotions, and lower negative emotions;

(2) Maladaptive perfectionism is associated with lower self-efficacy, lower positive emotions, and higher negative emotions;

(3) Level of self-efficacy, positive and negative emotions for maladaptive perfectionists does not have statistically significant differences from non-perfectionists indicators;

(4) There are no statistically significant differences in satisfaction with life indicators between groups of the adaptive, maladaptive perfectionism and non-perfectionism, however, adaptive perfectionism group shows higher levels of affective aspect of subjective well-being.

\section{References}

Bieling, P. J., Israeli, A. L., \& Antony, M. M. (2004). Is perfectionism good, bad, or both? Examining models of the perfectionism construct. Personality and Individual Differences, 36, 1373-1385.

Burns, D. (1980). Perfectionists script for self defeat. Psychology Today, November, 34-52.

Diener, E., Oishi, S., \& Lucas, R. E. (2002). Subjective well-being: The science of happiness and life satisfaction. In C. R. Snyder, \& S. J. Lopez (Eds.), Handbook of positive psychology. Oxford and New York: Oxford University Press. 
Diener, E., Oishi, S., \& Lucas, R. E. (2003). Personality, culture and subjective well-being: Emotional and cognitive evaluations of life. Annual Review of Psychology, 54, 403-425.

Egan, S. J., Piek, J., Dyck, M. J., \& Rees, C. S. (2007). The role of dichotomous thinking and rigidity in perfectionism. Behaviour Research \& Therapy, 45, 1813-1822.

Frost, R. O., Marten, P., Lahart, C., \& Rosenblate, R. (1990). The dimensions of perfectionism. Cognitive Theory and Research, 14, 449-468.

Ganske, K. H., \& Ashby, J. S. (2007). Perfectionism and career decision-making self-efficacy. Journal of Employment Counseling, 44 (1), 17-29.

Hewitt, P. L., \& Flett, G. L. (1991). Dimensions of perfectionism in unipolar depression. Journal of Abnormal Psychology, 100, 98-101.

Khawaja, N. G., \& Armstrong, K. A. (2005). Factor structure and psychometric properties of the Frost Multidimensional Perfecitonism Scale: Developing shorter versions using an Australian sample. Australian Journal of Psychology, 57(2), 129-138.

Lackaye, T., \& Margalit, M. (2008). Self-efficacy, loneliness, effort, and hope: Developmental differences in the experiences of students with learning disabilities and their non-learning disabled peers at two age groups. Learning Disabilities: A Contemporary Journal, 6(2), 1-20.

LoCicero, K. A., \& Ashby, J. S. (2000). Multidimensional perfectionism and self-reported self-efficacy in college students. Journal of College Student Psychotherapy, 15(2), 47-56.

Luszczynska, A., Gutiérrez-Dona, B., \& Schwarzer, R. (2005). General self-efficacy in various domains of human functioning: Evidence from five countries. International Journal of Psychology, 40, 80-89.

Maslovska, K., Voitkāne, S., Miezīte, S., \& Raščevska, M. (2005). Reliability and validity of the adaptation of the satisfaction with life scale in Latvia. Baltic Journal of Psychology, 6(2), 25-36.

Pavot, W., \& Diener, E. (2004). The subjective evaluation of well-being in adulthood: Findings and implications. Ageing International, 29(2), 113-135.

Rice, K. G., \& Stuart, J. (2010). Differentiating adaptive and maladaptive perfectionism on the MMPI-2 and MIPS revised. Journal of Personality Assessment, 92(2), 158-167.

Schwarzer, R., \& Jerusalem, M. (1995). Generalized self-efficacy scale. In J. Weinman, S. Wright, \& M. Johnson (Eds.), Measures in health psychology: A user's portfolio, causal and control beliefs (pp. 35-37). Windsor England: NFER-NELSON.

Schyns, B. (2004). The influence of occupational self-efficacy on the relationship of leadership behavior and preparedness for occupational change. Journal of Career Development, 30(4), 247-261.

Slaney, R. B., Mobley, M., Trippi, J., Ashby, J., \& Johnson, D. G. (1996). The Almost Perfect Scale-Revised (Unpublished manuscript, The Pennsylvania State University, University Park, PA).

Slaney, R. B., Rice, K. G., \& Ashby, J. S. (2002). A programmatic approach to measuring perfectionism: The almost perfect scales. In G. L. Flett, \& R. Hewitt (Eds.), Perfectionism (pp. 63-88). Washington, D.C.: American Psychological Association.

Stoeber, J., \& Otto, K. (2006). Positive conceptions of perfectionism: Approaches, evidence, challenges. Personality and Social Psychology Review, 10(4), 295-319.

Upmane, A. (2009). Apmierinātība ar dzīvi dažādu dzīves aspektu kontekstā (Satisfaction with life in context of various life aspects). Report made for 67th Conference of University of Latvia, Riga, January-April.

Wood, R., \& Bandura, A. (1989). Social cognitive theory of organizational management. Academy of Management Review, 14(3), 361-384. 